\title{
The effect of compliant prisms on subduction zone earthquakes and tsunamis
}

Gabriel C. Lotto ${ }^{a, 1}$, Eric M. Dunham ${ }^{a, b}$, Tamara N. Jeppson ${ }^{c}$, Harold J. Tobin ${ }^{c}$

a. Department of Geophysics, Stanford University, Stanford, CA, USA

b. Institute for Computational and Mathematical Engineering, Stanford University, Stanford, CA, USA

c. Geoscience Department, University of Wisconsin - Madison, Madison, WI, USA

1. Corresponding Author: glotto@stanford.edu

October 7, 2016

\begin{abstract}
Earthquakes generate tsunamis by coseismically deforming the seafloor, and that deformation is largely controlled by the shallow rupture process. Therefore, in order to better understand how earthquakes generate tsunamis, one must consider the material structure and frictional properties of the shallowest part of the subduction zone, where ruptures often encounter compliant sedimentary prisms. Compliant prisms have been associated with enhanced shallow slip, seafloor deformation, and tsunami heights, particularly in the context of tsunami earthquakes. To rigorously quantify the role compliant prisms play in generating tsunamis, we perform a series of numerical simulations that directly couple dynamic rupture on a dipping thrust fault to the elastodynamic response of the Earth and the acoustic response of the ocean. Gravity is included in our simulations in the context of a linearized Eulerian description of the ocean, which allows us to model tsunami generation and propagation, including dispersion and related nonhydrostatic effects. Our simulations span a three-dimensional parameter space of prism size, prism compliance, and sub-prism friction - specifically, the rate-and-state parameter $b-a$ that determines velocity-weakening or velocity-strengthening behavior. We find that compliant prisms generally slow rupture velocity and, for larger prisms, generate tsunamis more efficiently than subduction zones without prisms. In most but not all cases, larger, more compliant prisms cause greater amounts of shallow slip and larger tsunamis. Furthermore, shallow friction is also quite important in determining overall slip; increasing sub-prism $b-a$ enhances slip everywhere along the fault. Counterintuitively, we find that in simulations with large prisms and velocity-strengthening
\end{abstract}


friction at the base of the prism, increasing prism compliance reduces rather than enhances shallow slip and tsunami wave height.

Keywords: tsunami, compliant prism, tsunami earthquake, subduction zone, dynamic rupture

Funding: This work was supported by the National Science Foundation (EAR-1255439) and the Alfred P. Sloan Foundation (BR2012-097).

\section{Introduction}

Tsunamis induced by subduction zone earthquakes can be incredibly destructive events. Within the past few decades, tsunamis have been among the deadliest and costliest natural hazards [42], killing hundreds of thousands of people and doing billions of dollars of damage. Our study addresses tsunamigenic earthquakes by using dynamic rupture models to explore how the unique shallow structure of subduction zones, specifically sedimentary prisms, influences the rupture process and tsunami generation. To motivate this effort, we provide a brief overview of tsunamigenic earthquakes, as well as the current understanding of the material structure near the trench and frictional properties of the shallow plate interface, particularly as these relate to tsunami generation.

Tsunamigenic earthquakes can be broken into two major categories: great megathrust events and tsunami earthquakes [19]. The former category includes the 26 December 2004 Sumatra earthquake [43] and the 11 March 2011 Tohoku-Oki earthquake [41], both $M_{w}$ $9.0+$ earthquakes that generated large amounts of coseismic slip. The latter category includes events like the 17 July 2006 Java earthquake [1] and the 25 October 2010 Mentawai earthquake [28], which excited unusually large tsunamis for their body- and surface-wave magnitudes.

Coseismic slip during the Tohoku-Oki event displaced the seafloor near the Japan Trench by about 50 meters, according to bathymetric surveys, GPS measurements, and acoustic ranging data [10,39]. Seismic reflection data recorded days after the earthquake showed deformation in the sediments near the trench, indicating that fault rupture reached all the way to the seafloor [23]. Numerical modeling results indicate that rupture to the trench could occur even with shallow frictional conditions unfavorable to earthquake nucleation [26]. It is less clear that the Sumatra earthquake ruptured to the seafloor, as slip inversions with primarily deeper slip patches fit the sparse seismic and geodetic data reasonably well $[5,35]$. However, any slip that did occur near the trench could have contributed substantially to the resulting tsunami $[13,15]$. 
Tsunami earthquakes, first identified by Kanamori [19] in reference to the 1896 Sanriku, Japan, earthquake and the 1946 Aleutian Islands earthquake, also exhibit coseismic rupture through the shallow parts of subduction zones. Polet and Kanamori [36] identified several additional characteristics that tsunami earthquakes share: a slow rupture velocity that inefficiently releases high-frequency energy, a large distance between the earthquake source and the land, a subducting sedimentary layer with a small (under $40 \mathrm{~km}$ downdip width) accretionary prism at the trench, and rupture that propagates to very shallow depths. The most common explanation for the occurrence of tsunami earthquakes invokes the ease of deforming compliant accretionary prisms and subducted sediments, which are often present at subduction zone trenches $[20,36,44]$.

Generally speaking, the mechanism behind enhanced deformation in a compliant zone is that, in accordance with Hooke's Law, a given earthquake-induced stress change will cause greater strain and hence greater displacement in a more compliant material. In addition to the increased strain expected in the compliant prism, normal stress changes due to the presence of a bimaterial interface can affect the rupture process and facilitate unstable slip $[2,50]$. Ma and Beroza [30] found that normal stress variations on a dipping thrust fault due to free surface and bimaterial effects can create larger-than-normal stress drops when the hanging wall material is more compliant. However, material properties may not be solely responsible for large tsunamis; Bilek and Lay [3] pointed out that tsunami earthquakes have occurred both in regions with and without large sedimentary prisms, suggesting that frictional properties on the plate interface may also influence the rupture process.

Frictional properties are an important factor in determining rupture behavior on faults, but the frictional properties of the materials beneath subduction zone prisms are not fully understood. The conventional view of plate interfaces is that they are seismogenic only below a depth of about 5-10 kilometers [16]. Below this depth, fault materials have velocityweakening properties (they decrease in strength with increased slip velocity) and earthquakes can nucleate; above, unconsolidated clay-rich fault gouge is thought to be velocitystrengthening, inhibiting unstable slip. Our understanding of the upper limit of unstable slip is based in part on experiments showing that smectite-rich clay sediments dehydrate to form illite-rich material at $\sim 150{ }^{\circ} \mathrm{C}$ [14]. But experiments have shown that illite fault gouge may have velocity-strengthening properties [38]. Ultimately, it is likely that the depth range of velocity-weakening behavior is controlled by a combination of sediment composition, temperature, pore fluid pressure, and effective normal stress [7]. As a practical example from a real subduction zone, laboratory experiments on samples from the pelagic clay-based fault zone gouge of the Japan Trench found them to be predominantly velocity-strengthening, but with some amount of velocity-weakening and velocity-neutral behavior [17]. 


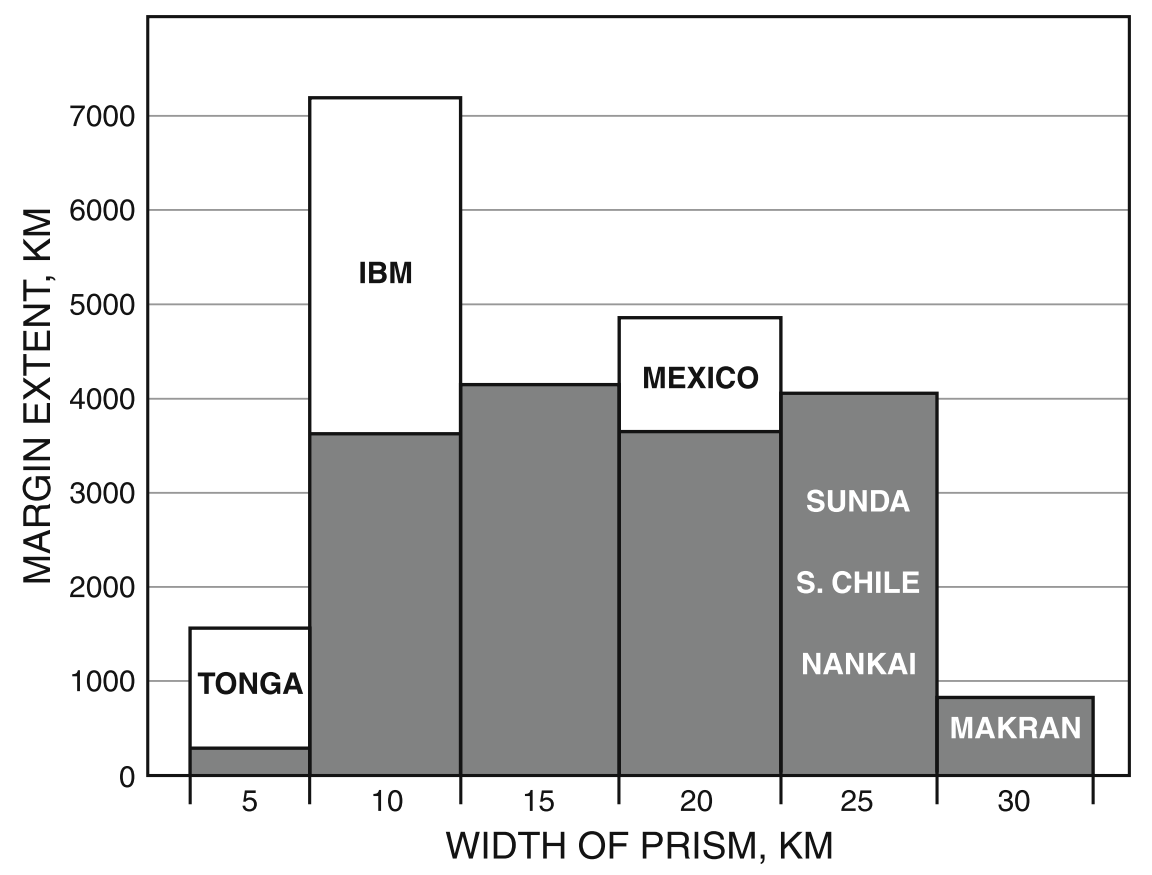

Figure 1: Histogram of prism widths in global subduction zones, compiled from seismic images of about $48 \%$ of the world's convergent margins. Unshaded areas (e.g., Tonga) represent prisms whose widths are uncertain due to poor seismic image quality. IBM refers to the Izu-Bonin-Mariana margin. After von Huene et al. [49]

The Japan Trench samples were also found to have low absolute friction coefficients $\left(f_{0}\right)$ between 0.20 and 0.26 for the fault zone [17]. These were comparable to measurements from other clay-rich subduction zone boundaries, including Nankai [24], Barbados [24], and Costa Rica [18]. In this study, we explore focus mainly on the rate-dependence effect of friction and not absolute friction (which we keep fixed at $f_{0}=0.6$, except in a set of simulations utilizing $f_{0}=0.2$ ), recognizing that the latter is important in determining the sensitivity of fault shear strength to changes in effective normal stress.

We return our discussion now to material structure, in order to justify the range of prism geometries and material properties to be explored in our simulations. Wide-angle seismic reflection surveys and potential-field modeling have imaged the structure of subduction zone boundaries in northern Japan [32,33], Nankai [22,34], Sunda [21,25], Cascadia [8,9], Chile $[27,47]$, and elsewhere. From a structural perspective, convergent margins are complex, and no simple model can explain them all. About 25 percent of the global span of major subduction zones are accreting margins, which widen over geologic time scales as lower-plate sediments transfer to the inner rock framework of the upper plate. Nonaccreting margins, identified by a trench axis that moves landward and a bedrock framework that extends 
offshore to within a few tens of kilometers of the trench, make up the other 75 percent [40]. Despite the differences in tectonic setting, geophysical data show that both accreting and nonaccreting margins have frontal prisms made up of actively deforming sedimentary material. The frontal prism is underlain by a sedimentary apron of shelf-slope deposits, which can include significant amounts of mass wasting debris [48]. Frontal prisms are typically 5-30 kilometers wide and can be several kilometers thick (Figure 1) [49]. The landward boundary of a frontal prism is defined by a mechanical backstop, a transition to a little-deforming middle prism (in the case of an accreting margin) or to a section of fragmented inner prism bedrock (in a nonaccreting margin) [40]. Our simulations span the typical width range of frontal prisms and ignore structural differences between accreting and nonaccreting margins.

Frontal prisms are composed of sedimentary materials that are more compliant than the surrounding bedrock framework. Modeling frontal prisms accurately requires the use of realistically low values for elastic moduli and wave speeds of prism sediments. Core samples from the frontal prism of the Japan Trench provide a specific example of how compliant these sediments can be. Ultrasonic p- and s-wave velocities were measured on core samples recovered at depths ranging from 690.4 to $818.5 \mathrm{mbsf}$ ( $\sim 7.6 \mathrm{~km}$ below sea level). Confining (effective) pressure was elevated stepwise from 1 to $18 \mathrm{MPa}$, and measurements showed a range of p-wave velocities $(\alpha)$ from 1.84 to $3.29 \mathrm{~km} / \mathrm{s}$ and a range of s-wave velocities $(\beta)$ from 0.80 to $1.16 \mathrm{~km} / \mathrm{s}$. The in situ values for $\alpha, \beta$, and $\alpha / \beta$ were estimated as 2.00 to $2.48 \mathrm{~km} / \mathrm{s}$, 0.89 to $1.10 \mathrm{~km} / \mathrm{s}$, and 2.05 to 2.48 , respectively [33]. The corresponding values for shear modulus and bulk modulus were 1.4 to $2.2 \mathrm{GPa}$ and 7.2 to $11.1 \mathrm{GPa}$, respectively, assuming an approximate in situ density of $1.8 \mathrm{~g} / \mathrm{cm}^{3}$ [4]. These results are consistent with the highly compliant material properties observed in frontal prisms in Cascadia [46], Nankai [37], Costa Rica [12], and Barbados [45]. Elastic moduli from deeper parts of the subduction zone are typically an order of magnitude or more larger. Our models span a wide range of material property values in the frontal prism, including these very compliant values.

\section{Dynamic Rupture Modeling}

We use 2D plane strain dynamic rupture models of a thrust fault intersecting the ocean in order to perform a parameter space survey of the factors that most strongly impact shallow slip and tsunamigenesis. Our numerical method [29] fully couples dynamic rupture to the elastodynamic response of the solid Earth and the ocean. Both compressibility and gravity are accounted for in the ocean, using a linearized Eulerian description to solve for perturbations about an initial hydrostatic state. Both ocean acoustic waves and tsunamis (including dispersion and nonhydrostatic effects in tsunami generation) are captured in this 


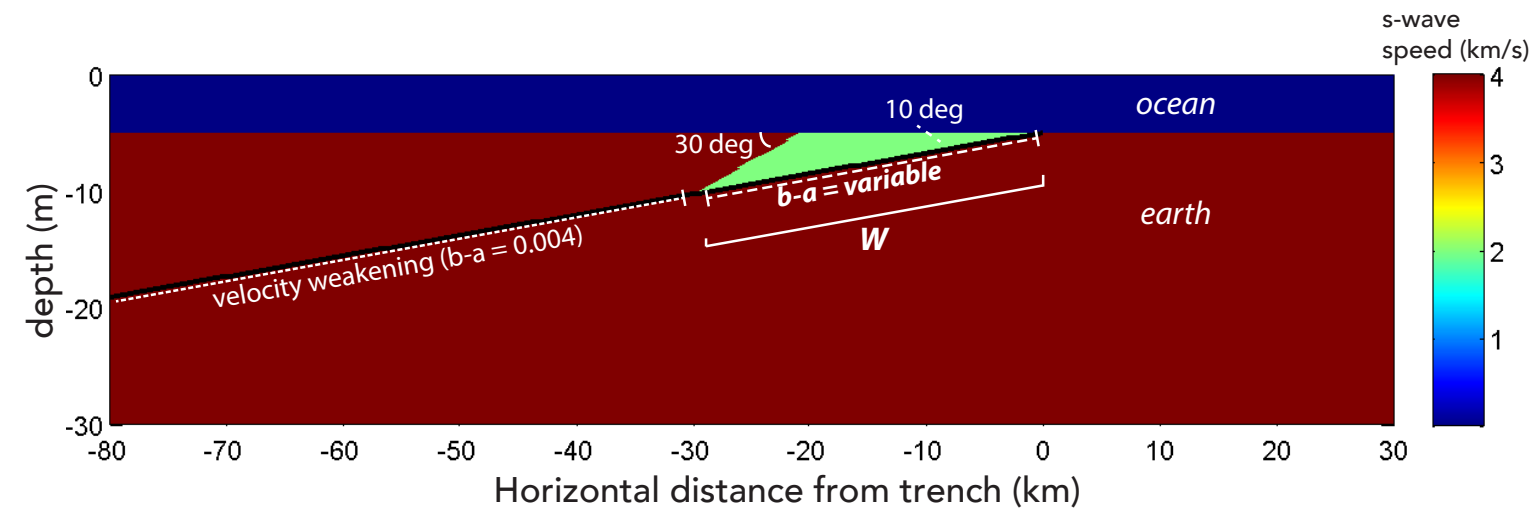

Figure 2: Geometry of the simulations in this study. A fault runs through the Earth with a $10^{\circ}$ dip angle, intersecting the seafloor, which has a flat bathymetry. In this image, $W=30$ $\mathrm{km}$ and $r$, the ratio of the shear wave speed in the background Earth to that in the prism, is equal to 2 .

approach. By dynamically coupling seafloor deformation to the ocean surface response, we can study the entire tsunami generation process without relying on approximations of initial conditions on sea surface height and depth-averaged horizontal particle velocity that are required in the commonly used shallow water wave theory.

We choose a geometry for our models that is as simple as possible while including some of the more pertinent features of subduction zone boundaries from around the world. In our geometry (Figure 2), a 144-km-long thrust fault cuts through the Earth with a $10^{\circ}$ dip angle, intersecting the ocean bottom at the subduction trench. The seafloor is flat and the ocean depth is $5 \mathrm{~km}$. (A study of tsunami generation in the presence of a sloping seafloor is deferred to future work.) The landward border of the prism dips at a $30^{\circ}$ angle from horizontal, typical of backstops that commonly define the edge of outer prisms in real subduction zones [49]. In this study, we do not allow for slip on splay faults that frequently demarcate prism backstops; all slip is confined to the plate boundary interface. The size of the prism is determined by the parameter $W$, which is defined as the downdip extent of the prism.

Material properties at every grid point are defined by three elastic parameters: density $\rho$, s-wave speed $\beta$, and p-wave speed $\alpha$. In the ocean, $\rho_{o}=1.0 \mathrm{~g} / \mathrm{cm}^{3}, \beta_{o}=0 \mathrm{~km} / \mathrm{s}$, and $\alpha_{o}=1.5 \mathrm{~km} / \mathrm{s}$; everywhere in the Earth except for the prism, $\rho_{e}=2.8 \mathrm{~g} / \mathrm{cm}^{3}, \beta_{e}=4.0$ $\mathrm{km} / \mathrm{s}$, and $\alpha_{e}=7.0 \mathrm{~km} / \mathrm{s}$, consistent with lower crustal materials. To select the material properties in the prism, we interpolate between the background values and values found in the compliant prism of the Japan Trench at the JFAST drilling site [33], namely $\rho_{l}=2.0$ $\mathrm{g} / \mathrm{cm}^{3}, \beta_{l}=0.9 \mathrm{~km} / \mathrm{s}$, and $\alpha_{l}=2.0 \mathrm{~km} / \mathrm{s}$. The three elastic parameters in the prism, $\rho_{p}, \beta_{p}$, 


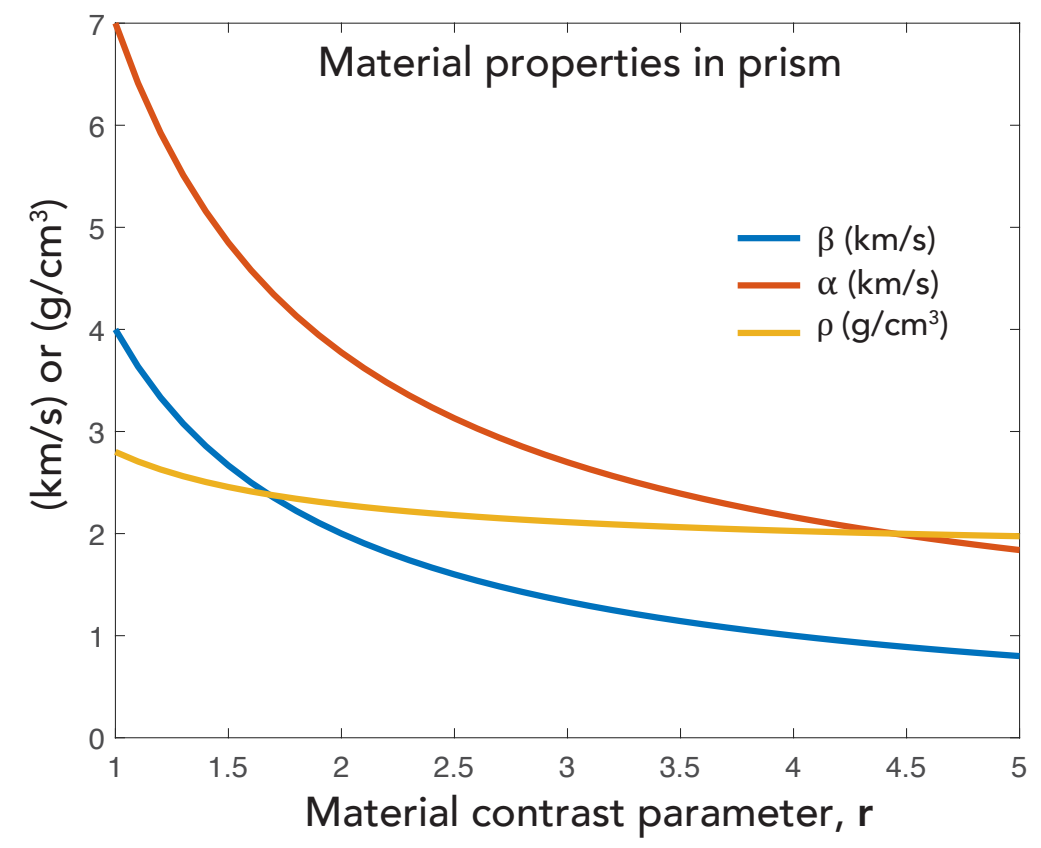

Figure 3: Dependence of $\beta_{p}, \alpha_{p}$, and $\rho_{p}$ on the material contrast parameter $r$.

and $\alpha_{p}$, are varied together by selecting a value for $r$, a dimensionless parameter defined as

$$
r=\frac{\beta_{e}}{\beta_{p}}
$$

Selecting the material contrast parameter $r$ sets a value for $\beta_{p}$, and then $\rho_{p}$ and $\alpha_{p}$ are calculated by interpolating between the background values in the Earth and those in the Japan trench. For example, $\rho_{p}$ is calculated as

$$
\rho_{p}=\rho_{l}+\left(\rho_{e}-\rho_{l}\right) \frac{\left(1-\beta_{l} / \beta_{p}\right)}{\left(r-\beta_{l} / \beta_{p}\right)}
$$

and $\alpha_{p}$ is calculated similarly (Figure 3). By selecting different values of $r$, we sweep through not only parameters but also ratios of parameters, including $\alpha / \beta$, which ratio is 1.75 in the background rock and 2.22 in the Japan Trench. We also mention that while the present study is limited to the elastic response of off-fault materials, prism sediments are also weak in terms of their susceptibility to inelastic deformation, which may impact the rupture process in real subduction zones [31].

Rupture on the fault is governed by the rate-and-state friction law in a differential form [26]:

$$
\frac{d \tau}{d t}=\frac{a \bar{\sigma}}{V} \tanh \left(\frac{\tau}{a \bar{\sigma}}\right) \frac{d V}{d t}-\frac{V}{l}\left[|\tau|-\bar{\sigma} f_{s s}(V)\right]
$$


with the steady-state friction coefficient given by

$$
f_{s s}(V)=f_{0}-(b-a) \ln \left(V / V_{0}\right),
$$

where $\tau$ is the shear strength of the fault, $\bar{\sigma}$ is the effective normal stress, $V$ is the slip velocity, $l=0.8 \mathrm{~m}$ is the state evolution distance, $V_{0}=1 \mu \mathrm{m} / \mathrm{s}$ is the reference velocity, and $b$ and $a$ are dimensionless parameters. For positive $b-a$, increases in $V$ decrease steady state friction $f_{s s}$, leading to potentially unstable slip and earthquake nucleation. For negative $b-a$, increasing $V$ increases $f_{s s}$, inhibiting unstable slip. In our models, we apply velocity weakening $(b-a=0.004)$ friction everywhere except in the region beneath the prism. On the shallow fault segment defined by $W$, we vary $b$ so that the fault ranges from velocity weakening properties $(b-a=0.004)$ to velocity strengthening properties $(b-a=-0.004)$. The friction law (4) does not let shear stress instantaneously respond to changes in effective normal stress. This avoids ill-posedness that can occur in bimaterial slip problems for friction laws in which $\tau$ is directly proportional to the instantaneous value of $\bar{\sigma}$.

We set $f_{0}$, the friction coefficient for steady sliding at $V_{0}$, to a constant $f_{0}=0.6$, despite some evidence (cited above) that absolute friction may be lower in clay-rich subduction zones. Though the effects of varying absolute fault friction are largely out of the scope of this paper, the simulations we ran using $f_{0}=0.2$ show somewhat lower slip at the trench but qualitatively similar results as when $f_{0}=0.6$ (see Supplementary Figure 1). The decreased slip at the trench is due to the fact that initial shear stress must be set lower when the absolute friction coefficient is lower. Differences between $f_{0}=0.6$ and $f_{0}=0.2$ are more pronounced in models with velocity-weakening friction and more compliant prisms, i.e., models with higher slip at the trench.

In order to account for poroelastic changes in pore pressure, $\Delta p$, as a response to changes in total normal stress, $\Delta \sigma$, we use the linear relation $\Delta p=B \Delta \sigma$, with $B=0.6$. The poroelastic effect alters stress as

$$
\bar{\sigma}=\bar{\sigma}_{0}+(1-B) \Delta \sigma,
$$

which serves to partially buffer the changes in effective normal stress. Equation 5 is a limiting case of a model [6] where the fault is surrounded by highly damaged material; in that limit, $B$ is Skempton's coefficient.

Initial effective normal stress $\bar{\sigma}_{0}$ is calculated as the difference between normal stress in the Earth and pore pressure. Normal stress on the fault is set to lithostatic - a decent approximation given the shallow fault dip - and pore pressure is hydrostatic. Effective normal stress increases with depth to a maximum of $\bar{\sigma}_{0}=40 \mathrm{MPa}$, at which point pore pressure 
increases lithostatically. Initial shear stress on the fault, $\tau_{0}$, is $\tau_{0}=0.6 \bar{\sigma}_{0}$. Earthquakes are nucleated by perturbing shear stress on the fault at a depth of $13 \mathrm{~km}$ below the seafloor, 75 $\mathrm{km}$ away from the trench.

We perform a parameter space survey in three dimensions: $r, W$, and $b-a$ at the base of the prism. The values we use are $r=1,2,3,4,5 ; W=10,20,30 \mathrm{~km} ;$ and $b-a=$ $0.004,0.002,0.000,-0.002,-0.004$.

For most simulations, we use a grid spacing of $200 \mathrm{~m}$ in both the vertical and horizontal directions. For the majority of our simulations, mesh refinement leads to little or no difference (less than $\sim 2 \%$ ) in final slip and tsunami height. However, at the edge of parameter space where $W=30 \mathrm{~km}$ and $b-a= \pm 0.004$, doubling the mesh resolution leads to a more substantial (greater than $\sim 5 \%$ ) change in slip. In those cases (i.e., Figure 7a-b,i-j), we show the results of simulations with $100 \mathrm{~m}$ grid spacing.

\section{Results and Discussion}

The parameter space survey reveals that prism size, compliance, and friction each help determine fault slip and tsunami height, and that the parameters $r, W$, and $b-a$ interact with each other in significant and sometimes unexpected ways. Most notably, we find that in most but not all cases, the presence of a compliant prism causes enhanced slip which in turn increases tsunami heights. However, compliant prisms also play several other roles in the earthquake rupture process.

For example, we find that for prisms of all sizes, the rupture velocity slows significantly as rupture reaches the prism, due to lower shear speeds (Figure 4). Sub-prism friction can influence rupture velocity by inducing supershear propagation at the base of the prism when friction is velocity-weakening (compare Figure $4 \mathrm{c}$ and $\mathrm{d}$ ). Models with $r=1$, i.e., no material property contrast between the prism and surrounding rock, have sub-Rayleigh rupture velocities that are fairly constant with depth or speed up slightly near the trench (Figure $4 \mathrm{a}$ and $\mathrm{b}$ ). Note that simulations with $r=1$ have no compliant prism, but they do have frictional properties determined by $W$ and $b-a$; this accounts for the difference in results between Figure $4 \mathrm{a}$ and $\mathrm{b}$.

However, earthquakes that rupture through compliant prisms slow considerably as they approach the trench, limited by the shear-wave speed in the prism (Figure 4c and d). Note that even though $r$ largely controls the rupture velocity, slip velocity and total slip are strongly influenced by shallow friction. For example, comparing Figure 4c and d we see that in both cases rupture velocity slows in the $30-\mathrm{km}$ region at the base of the prism due to the compliant material properties within the prism. But only in $d$, the simulation where 

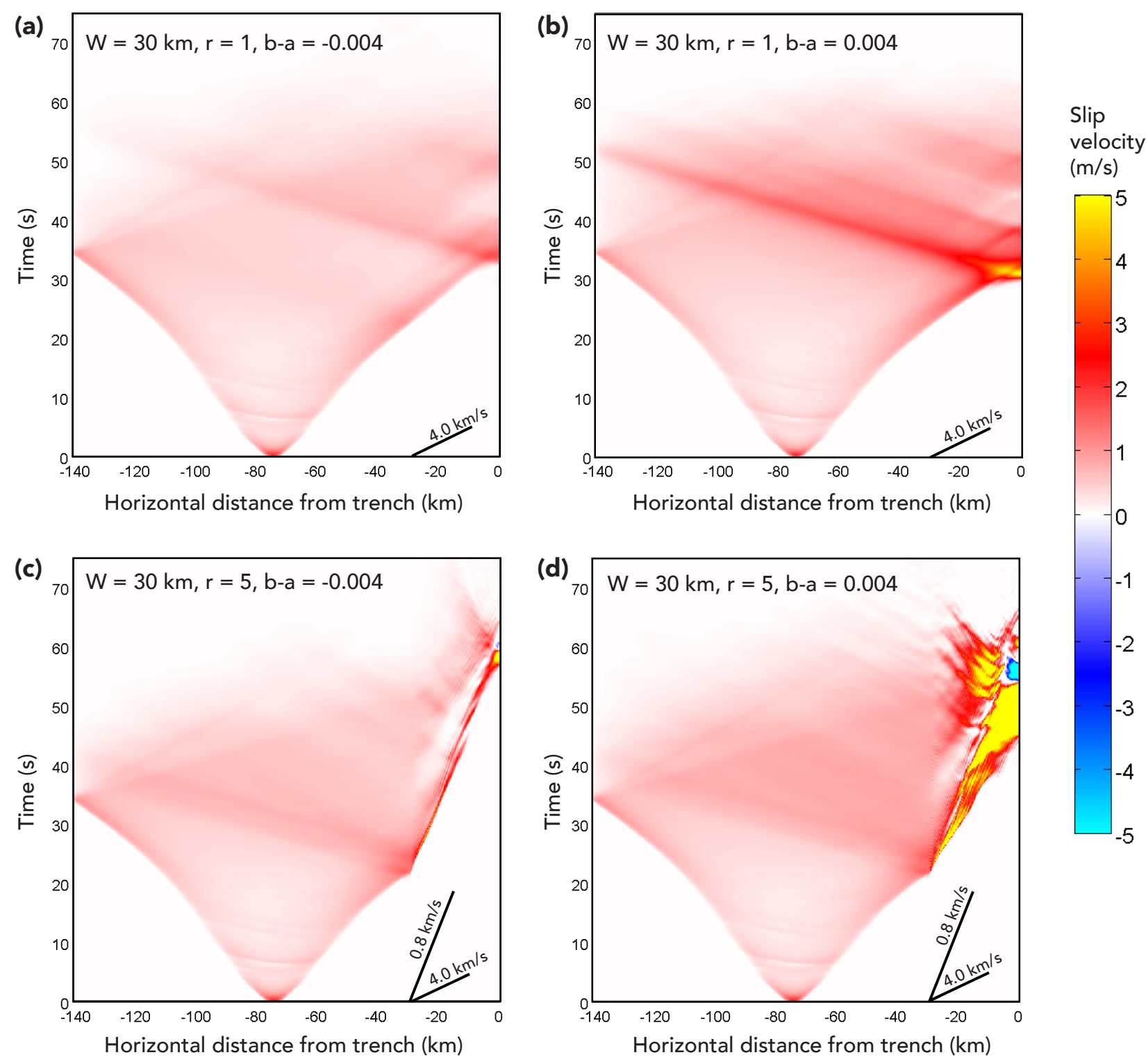

Figure 4: Time-space plots of slip velocity for four different simulations, all with $W=30 \mathrm{~km}$. Dark black lines are drawn at the representative shear wave speeds in the medium, $4.0 \mathrm{~km} / \mathrm{s}$ where there is no prism and $0.8 \mathrm{~km} / \mathrm{s}$ in the prism in simulations where $r=5$. (a) $r=1$, $b-a=-0.004$ beneath the prism. Rupture velocity is consistent at all depths along the fault. (b) $r=1, b-a=0.004$ beneath the prism. Rupture velocity is consistent at all depths, but slip velocity increases due to velocity-weakening friction. (c) $r=5, b-a=-0.004$ beneath the prism. Rupture slows appreciably on the fault at the base of the prism due to highly compliant material properties. (d) $r=5, b-a=0.004$ beneath the prism. Rupture slows appreciably but slip velocity is greatly enhanced. 

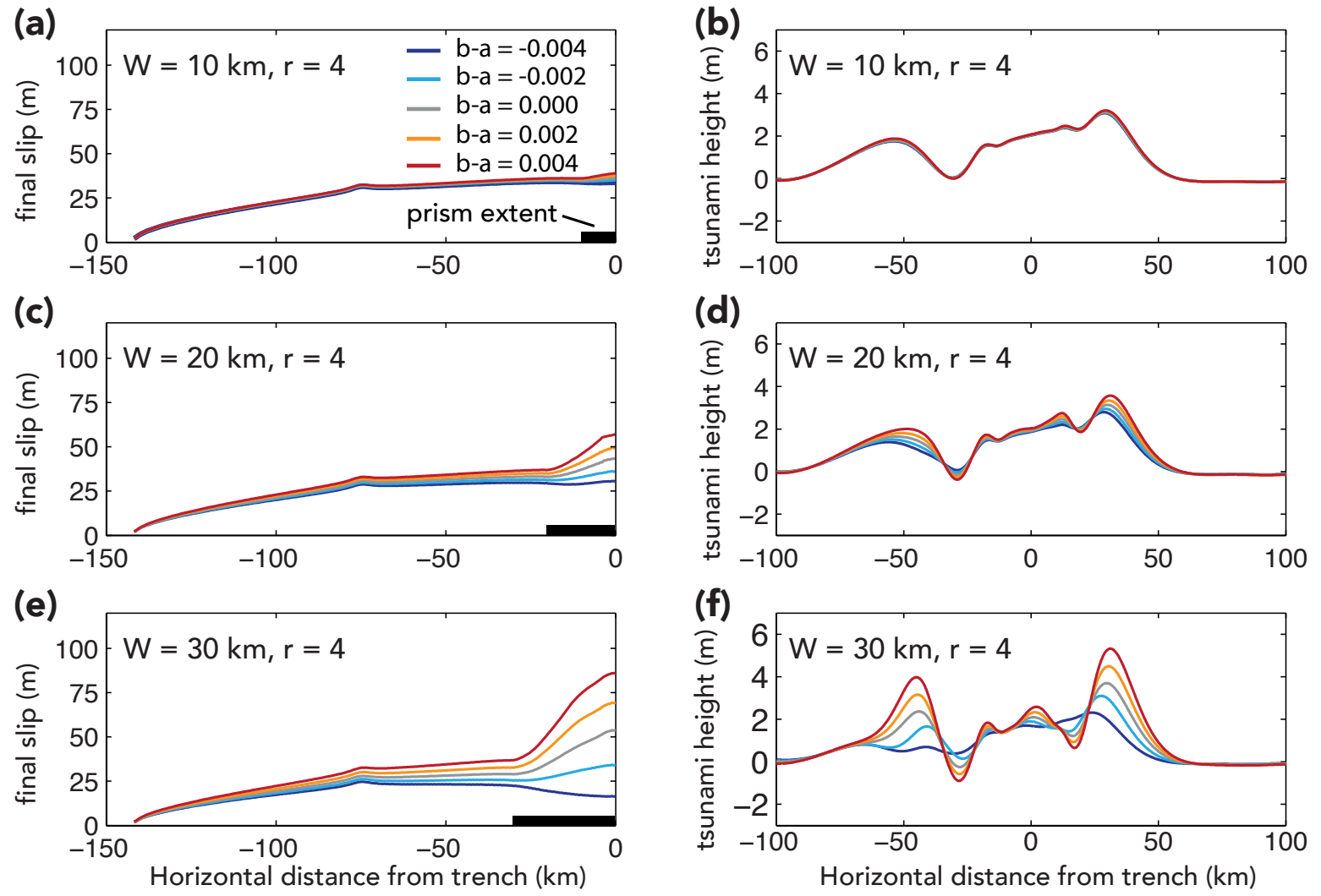

Figure 5: Total slip and tsunami height (vertical displacement at the sea surface) for simulations with $r=4$, plotted at time $t=250 \mathrm{~s}$. In each plot, $W$ is held fixed and friction is varied as $b-a=-0.004,-0.002,0,0.002,0.004$. (a) and (b): $W=10 \mathrm{~km}$ and changing shallow friction has little effect on slip and tsunami height. (c) and (d): $W=20 \mathrm{~km}$ and changing shallow friction has a moderate effect on slip and tsunami height. (e) and (f): $W=30 \mathrm{~km}$ and changing shallow friction has a great effect on slip and tsunami height.

sub-prism friction is velocity weakening, does slip velocity notably increase.

We present a series of simulations holding $W$ and $r$ constant while varying shallow $b-a$. We find that moving from velocity-strengthening to velocity-weakening friction - increasing the parameter $b-a-$ on the fault at the base of the prism resulted in greater amounts of slip, not only near the trench but also deeper down along the fault (e.g., Figure 5). The reason for this enhanced slip along the entire fault can be seen by comparing Figure 4a and $\mathrm{b}$; when the fault is velocity-weakening at the trench (as in b), the rupture propagates back down the fault after reaching the trench. Increasing $b-a$, i.e., enhancing slip, also leads to the generation of larger tsunamis. Tsunami height is defined herein as vertical displacement at the sea surface at time $t=250 \mathrm{~s}$, by which point all ocean acoustic waves have propagated out of the domain. The time of measurement is somewhat arbitrarily chosen, but since our simulations are in $2-\mathrm{D}$, there is no amplitude decay from geometric spreading and only a 
slight amount from dispersion. The effects of modifying $b-a$ are more pronounced for larger prisms than for smaller prisms (Figure 5), and in this sense we can view prism size $W$ as having an amplifying effect on enhanced slip and tsunamigenesis.

Separately, we look at a series of simulations where we hold $W$ and $b-a$ constant and vary the prism compliance, $r$. The results of these simulations turn out to be highly dependent on the choice of $b-a$. For example, when $b-a \geq-0.002$, increasing the compliance of the prism leads to greatly enhanced slip and significantly larger tsunamis (see Figure $6 \mathrm{a}-\mathrm{j}$ and Figure $7 \mathrm{c}-\mathrm{j}$ ). This phenomenon is true for prisms of any considerable size. That more compliant prisms tend to enhance shallow slip and tsunamigenesis for most choices of shallow $b-a$ and $W$ is unsurprising, given the general consensus in the tsunami community that compliant sedimentary material is often associated with tsunami earthquakes (e.g., [20,36]).

However, we find that in certain circumstances increasing $r$ actually leads to decreased slip. In particular, when $W=30 \mathrm{~km}$ and $b-a=-0.004$ (velocity-strengthening shallow friction), prism compliance is negatively correlated with shallow slip (Figure 7a). This is an unintuitive result given the role compliant prisms are generally thought to play in enhancing tsunamigenesis via shallow deformation. We have found no clear explanation for this result, but we offer some observations from slip history plots (see Supplementary Figure 2). When $W=30 \mathrm{~km}$ and $b-a=-0.004$, the simulation with no compliant prism $(r=1)$ results in a rupture that propagates smoothly through the region with velocity-strengthening friction. But with a compliant prism $(r=3$ and $r=5)$, the rupture slows significantly in the prism and partially reflects, propagating back down the fault. Meanwhile, the upward-propagating rupture front decreases in slip velocity and barely makes it all the way through to the trench. The most obvious difference between models with and without a compliant prism is that with a compliant prism, slip velocity goes nearly to zero below the rupture front as the rupture propagates through the prism. By the time the rupture reaches the trench, there is a deficit of slip in the shallow part of the fault that is never overcome.

We note that for low values of $r$, slip is nearly uniform in the shallow portion of the fault, only a few meters higher at the trench than at depth (see, e.g., the grey curve in Figure 6i). This result might, at first, seem to conflict with Geist and Dmowska [11], who found, in their study of static elastic solutions for constant stress drop cracks on dipping faults, that slip should take its maximum value at the free surface. However, in our simulations stress drop is not constant on the fault but rather decreases toward the trench, which may account for some of the difference. Additionally, our simulations include inertia whereas Geist and Dmowska calculated a static displacement field from an ideal crack model.

Across our simulations, there is no straightforward linear relation between compliance 
(a)

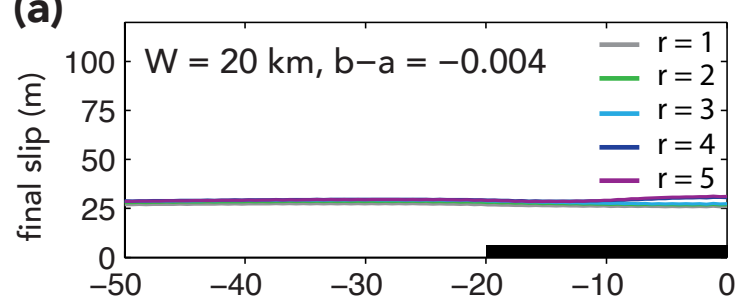

(c)

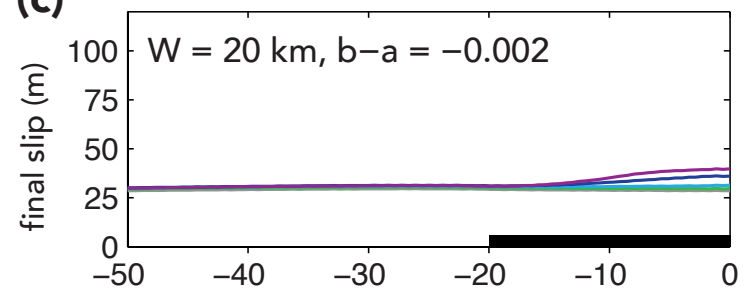

(e)

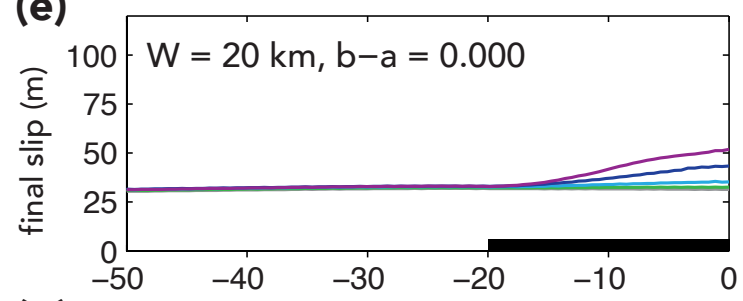

(g)

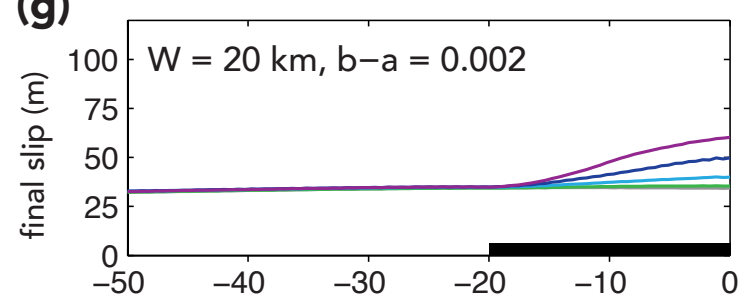

(i)

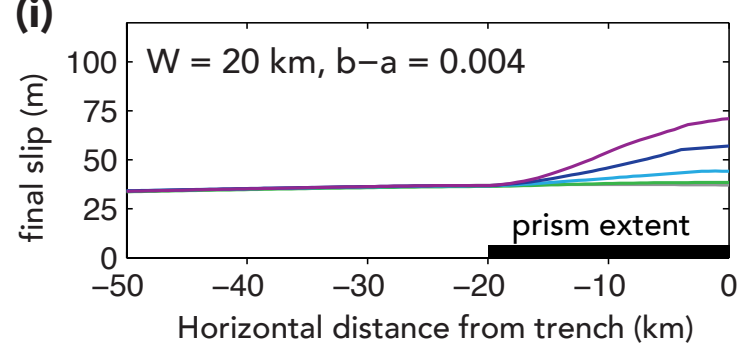

(b)

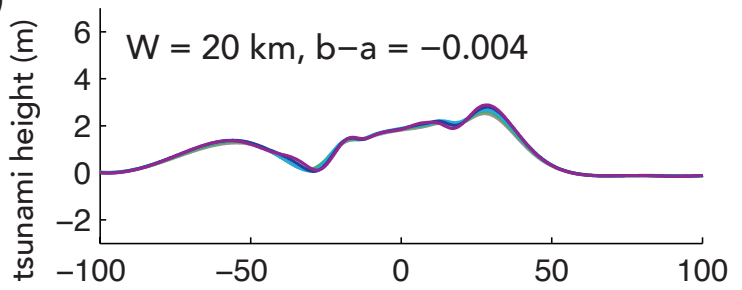

(d)

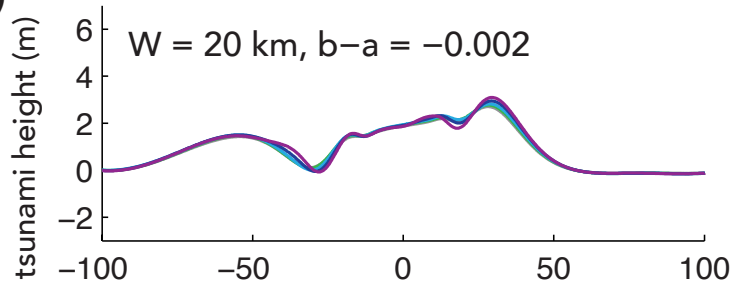

(f)

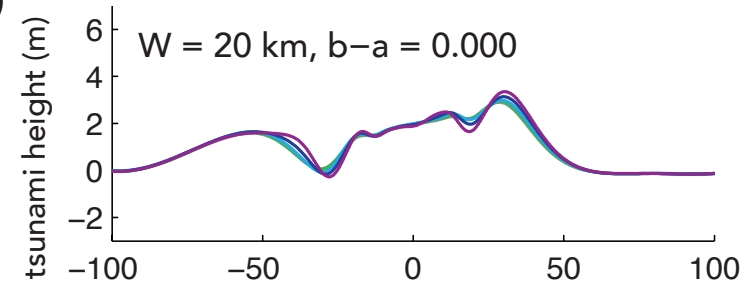

(h)

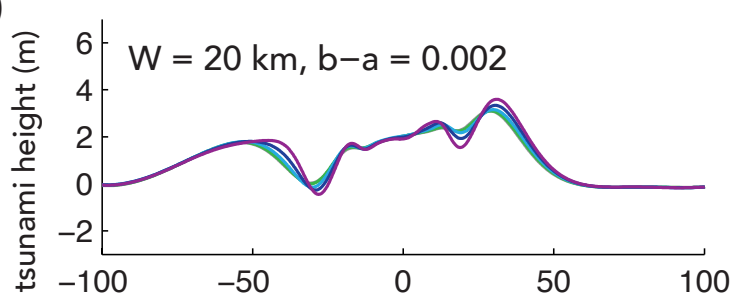

(j)

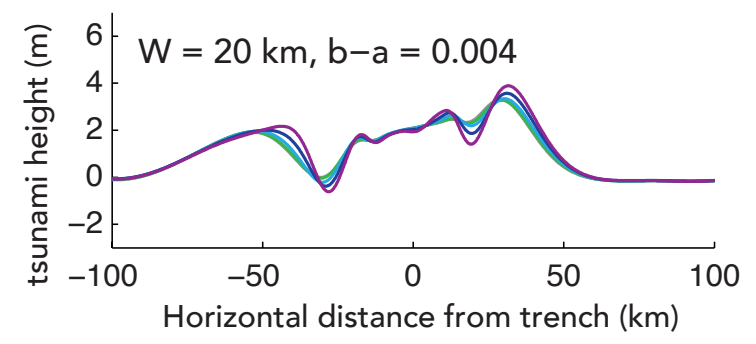

Figure 6: Total slip and tsunami height for simulations with $W=20 \mathrm{~km}$, plotted at time $t=250 \mathrm{~s}$. In each plot, $b-a$ is held fixed and prism compliance is varied as $r=1,2,3,4,5$. For prisms of width $W=20 \mathrm{~km}$ and smaller, increases in prism compliance always lead to more slip and greater amplitude tsunamis, independent of shallow $b-a$. Downdip of the prism, slip is nearly equivalent for all simulations with the same value of $b-a$. 

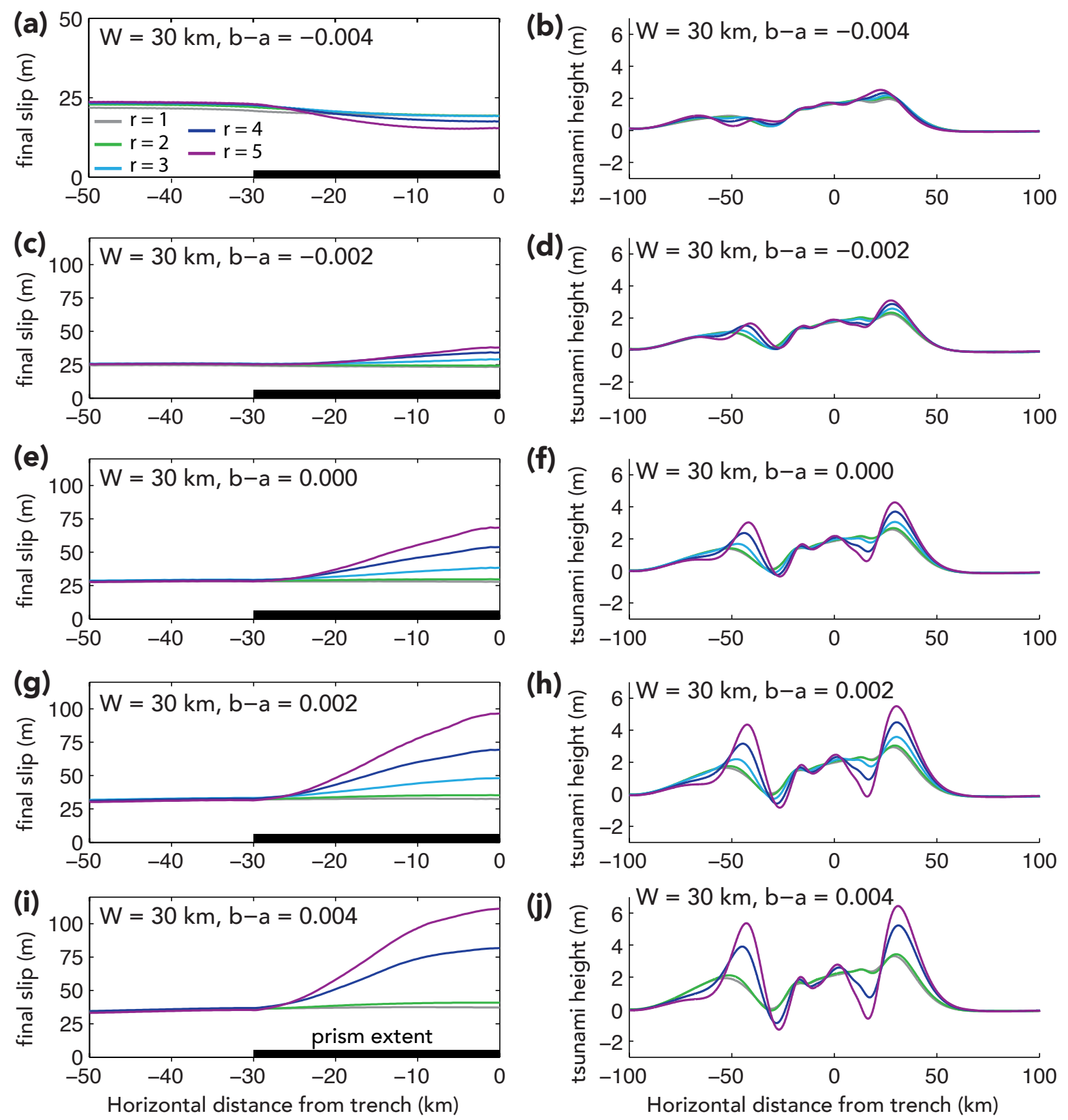

Figure 7: Total slip and tsunami height for simulations with $W=30 \mathrm{~km}$, plotted at time $t=250 \mathrm{~s}$. In each plot, $b-a$ is held fixed and prism compliance is varied as $r=1,2,3,4,5$. For larger prisms $(W=30 \mathrm{~km})$, increases in prism compliance sometimes lead to more slip and greater amplitude tsunamis, for example when $b-a \geq-0.002$ ( (c)-(j)). However, when $b-a=-0.004$, more compliant prisms actually experience less slip ( (a) and (b)). In (a), the vertical axis is compressed for emphasis. Downdip of the prism, slip is nearly equivalent for all simulations with the same value of $b-a$. 
and shallow slip as might have been anticipated from linear elasticity in a homogeneous medium. For example, in Figure 6(i), when $r=2$ the ratio of the shear modulus in the surrounding Earth to that in the prism is $44.8 \mathrm{GPa} / 9.1 \mathrm{GPa} \approx 4.9$, but the shallow slip is nearly identical to the $r=1$ case. Only when that ratio gets much more extreme -11.9 for $r=3,22.1$ for $r=4,35.5$ for $r=5$ - does slip increase significantly.

We can quantify the time-dependent earthquake source process using seismic potency per distance along strike, $P$, defined as

$$
P(t)=\int_{-L}^{0} s(x, t) d x
$$

where $s$ is slip and $x$ follows the downdip axis over fault length $L=144 \mathrm{~km}$. Potency is equivalent to moment per unit rigidity, and avoids any ambiguities in choosing a shear modulus when, for instance, there are different materials on opposite sides of the fault. We also define potency rate, $\dot{P}=d P / d t$. In Figure 8 , we plot $\dot{P}$ as a function of time for various simulations with $W=30 \mathrm{~km}$, which lets us observe differences in slip history for different sets of parameters. For $b-a \geq-0.002$, we see a peak in potency rate that is dependent on prism compliance, where more compliant prisms see a delayed peak in $\dot{P}$ due to rupture velocity decreasing with larger $r$. Naturally, this peak in $\dot{P}$ is greater for higher values of $b-a$. For the case where $b-a=-0.004$, the correlation between $r$ and the time of peak $\dot{P}$ is less clear, especially for the most compliant model. For $r=5$, the rupture slows significantly but does not generate enough shallow slip to appear as a peak in potency rate.

Finally, in order to get a measure of an earthquake's efficiency at generating tsunamis, we define the dimensionless quantity $\varepsilon$ as

$$
\varepsilon=\frac{h_{\max }}{P / L}=\frac{h_{\max }}{\langle s\rangle}
$$

where $h_{\max }$ is the maximum tsunami height at a given time. We note that $P / L$ is the average slip on the fault, $\langle s\rangle$. Tsunami efficiency, $\varepsilon$, is measured at time $t=250 \mathrm{~s}$, at which point all higher-frequency acoustic waves oscillating in the compressible ocean have propagated out of the domain. A larger value of $\varepsilon$ indicates that for a given set of parameters, the resulting tsunami is large relative to the amount of slip along the entire fault. Figure 9 shows that in medium and large prisms $(W=20,30 \mathrm{~km})$, tsunami efficiency increases with $r$ and with shallow $b-a$. In smaller prisms $(W=10 \mathrm{~km}), \varepsilon$ has a small but negative correlation with $r$. Small compliant prisms cause increased slip at the trench but slightly decreased slip at depth, leading to average slip that is about equivalent to models with no compliant prism. This slip pattern actually leads to very slightly lower maximum tsunami heights, and thus 

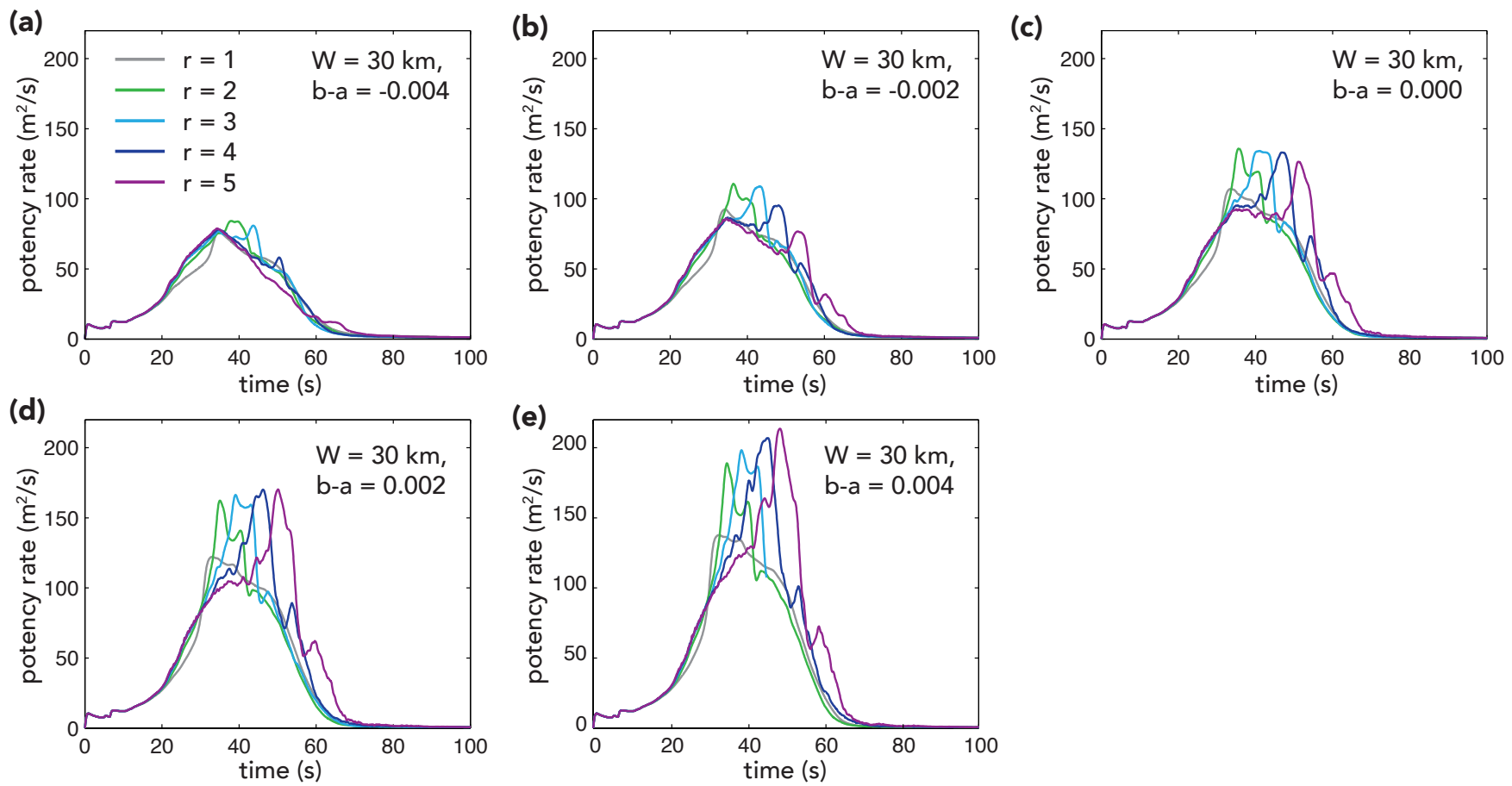

Figure 8: Potency rate $\dot{P}$ for $W=30 \mathrm{~km}$. For $b-a \geq-0.002$, more compliant prisms lead to later peaks in $\dot{P}$. This phenomenon is less clear when $b-a=-0.004$.

a decreased $\varepsilon$.

\section{Conclusions}

Earthquakes that rupture through compliant prisms can exhibit many of the characteristics of tsunami earthquakes. On the fault at the base of the prism, rupture velocity slows significantly, limited by the lower shear wave speed of prism sediments. Shallow slip usually increases compared to models without a prism, enhancing seafloor deformation and creating larger tsunamis. With larger and more compliant prisms and more favorable frictional conditions, these earthquakes can generate tsunamis very efficiently with respect to the total slip they produce. Smaller compliant prisms tend to have little to no effect on tsunami height, regardless of friction and material properties.

Figure 10 summarizes the effects of the material contrast parameter $r$, prism size $W$, and shallow rate-and-state friction parameter $b-a$ on the rupture process. In most parts of parameter space, increasing prism compliance $r$ leads to enhanced shallow slip and larger tsunamis. However, in simulations with velocity-strengthening friction $(b-a=-0.004)$ and a large prism $(W=30 \mathrm{~km})$, the presence of a more compliant prism reduces shallow slip. 

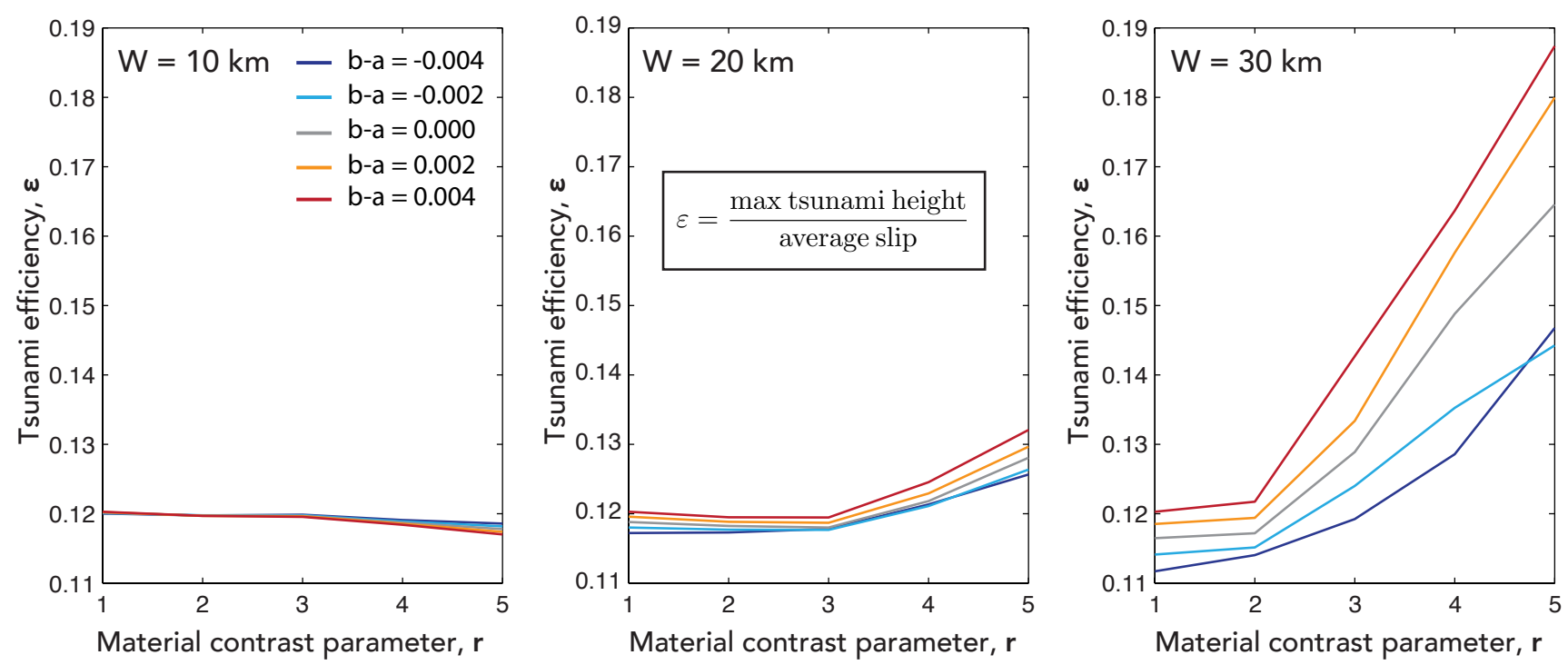

Figure 9: Tsunami efficiency, defined as the ratio of maximum tsunami height (at time $t=250 \mathrm{~s}$ ) to average slip. Earthquakes that rupture through medium and large prisms more efficiently generate tsunamis when $b-a$ and $r$ are larger.

Increasing the rate-and-state parameter $b-a$ at the base of the prism leads to increased slip not only beneath the prism but also deeper down along the entire fault. Increasing the size of the prism, $W$, tends to amplify the effects of changing $r$ and $b-a$.

The wide range of results produced by varying just these three parameters points to the importance of studying subduction zone earthquakes with realistically complex numerical models, and of continuing to gather data on frictional and material properties of prisms in convergent margins where tsunamis may pose a significant threat to local populations.

\section{References}

[1] Charles J Ammon, Hiroo Kanamori, Thorne Lay, and Aaron A Velasco. The 17 July 2006 Java tsunami earthquake. Geophysical Research Letters, 33(24), 2006.

[2] David J Andrews and Yehuda Ben-Zion. Wrinkle-like slip pulse on a fault between different materials. Journal of Geophysical Research, 102:553-571, 1997.

[3] Susan L Bilek and Thorne Lay. Tsunami earthquakes possibly widespread manifestations of frictional conditional stability. Geophysical Research Letters, 29(14), 2002.

[4] Frederick M Chester, Junichiro Mori, Nawo Eguchi, and Sean Toczko. Expedition 343/343t scientists: Site c0019. Technical report, The Expedition 343/343T Scientists, 


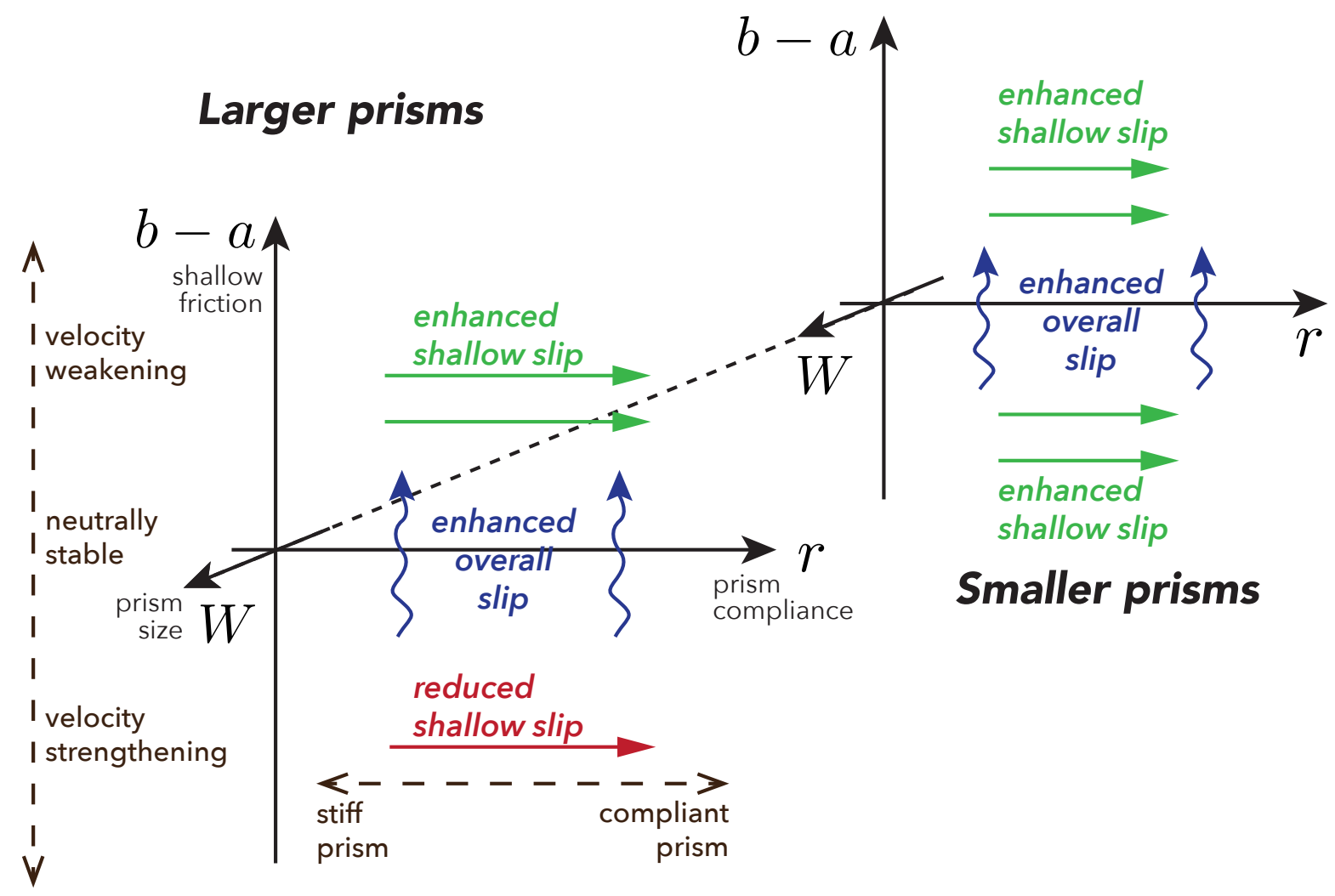

Figure 10: Schematic of parameter space and the effects of $r, W$, and $b-a$ on fault slip. For larger prisms, increasing $r$ leads to enhanced shallow slip when $b-a$ is positive, but leads to reduced shallow slip when $b-a$ is negative. For smaller prisms, increases in $r$ always result in more shallow slip. Increasing $b-a$ enhances slip on all parts of the fault. Increasing $W$ amplifies the effects of $r$ and $b-a$. 
Proc. IODP, 343/343T. Integrated Ocean Drilling Program Management International, Inc, Tokyo, 10.2204/iodp.proc.343343T.103.2013, 2013.

[5] Mohamed Chlieh, Jean-Philippe Avouac, Vala Hjorleifsdottir, Teh-Ru Alex Song, Chen Ji, Kerry Sieh, Anthony Sladen, Helene Hebert, Linette Prawirodirdjo, Yehuda Bock, et al. Coseismic slip and afterslip of the great Mw 9.15 Sumatra-Andaman earthquake of 2004. Bulletin of the Seismological Society of America, 97(1A):S152-S173, 2007.

[6] Massimo Cocco and James R Rice. Pore pressure and poroelasticity effects in Coulomb stress analysis of earthquake interactions. Journal of Geophysical Research: Solid Earth, 107(B2), 2002.

[7] Sabine A M den Hartog and Christopher J Spiers. Influence of subduction zone conditions and gouge composition on frictional slip stability of megathrust faults. Tectonophysics, 600:75-90, 2013.

[8] Sean W Fleming and Anne M Tréhu. Crustal structure beneath the central Oregon convergent margin from potential-field modeling: Evidence for a buried basement ridge in local contact with a seaward dipping backstop. Journal of Geophysical Research: Solid Earth, 104(B9):20431-20447, 1999.

[9] Ernst R Flueh, Michael A Fisher, Joerg Bialas, Jonathan R Childs, Dirk Klaeschen, Nina Kukowski, Tom Parsons, David W Scholl, Uri ten Brink, Anne M Tréhu, et al. New seismic images of the Cascadia subduction zone from cruise SO108 - ORWELL. Tectonophysics, 293(1):69-84, 1998.

[10] Toshiya Fujiwara, Shuichi Kodaira, Yuka Kaiho, Narumi Takahashi, and Yoshiyuki Kaneda. The 2011 Tohoku-Oki earthquake: Displacement reaching the trench axis. Science, 334(6060):1240-1240, 2011.

[11] Eric L Geist and Renata Dmowska. Local tsunamis and distributed slip at the source. In Seismogenic and Tsunamigenic Processes in Shallow Subduction Zones, pages 485-512. Springer, 1999.

[12] G L Gettemy and Harold J Tobin. Tectonic signatures in centimeter-scale velocityporosity relationships of Costa Rica convergent margin sediments. Journal of Geophysical Research: Solid Earth, 108(B10), 2003.

[13] Sean PS Gulick, James A Austin Jr, Lisa C McNeill, Nathan LB Bangs, Kylara M Martin, Timothy J Henstock, Jonathan M Bull, Simon Dean, Yusuf S Djajadihardja, 
and Haryadi Permana. Updip rupture of the 2004 Sumatra earthquake extended by thick indurated sediments. Nature Geoscience, 4(7):453-456, 2011.

[14] John Hower, Eric V Eslinger, Mark E Hower, and Edward A Perry. Mechanism of burial metamorphism of argillaceous sediment: 1. Mineralogical and chemical evidence. Geological Society of America Bulletin, 87(5):725-737, 1976.

[15] Judith Hubbard, Sylvain Barbot, Emma M Hill, and Paul Tapponnier. Coseismic slip on shallow décollement megathrusts: implications for seismic and tsunami hazard. EarthScience Reviews, 141:45-55, 2015.

[16] Roy D Hyndman, Makoto Yamano, and Dan A Oleskevich. The seismogenic zone of subduction thrust faults. Island Arc, 6(3):244-260, 1997.

[17] Matt J Ikari, Jun Kameda, Demian M Saffer, and Achim J Kopf. Strength characteristics of Japan Trench borehole samples in the high-slip region of the 2011 Tohoku-Oki earthquake. Earth and Planetary Science Letters, 412:35-41, 2015.

[18] Matt J Ikari, André R Niemeijer, Christopher J Spiers, Achim J Kopf, and Demian M Saffer. Experimental evidence linking slip instability with seafloor lithology and topography at the Costa Rica convergent margin. Geology, 41(8):891-894, 2013.

[19] Hiroo Kanamori. Mechanism of tsunami earthquakes. Physics of the Earth and Planetary Interiors, 6(5):346-359, 1972.

[20] Hiroo Kanamori and Masayuki Kikuchi. The 1992 Nicaragua earthquake: a slow tsunami earthquake associated with subducted sediments. Nature, 361(6414):714-716, 1993.

[21] Frauke Klingelhoefer, M-A Gutscher, S Ladage, J-X Dessa, David Graindorge, D Franke, Camille André, Haryadi Permana, T Yudistira, and Ajay Chauhan. Limits of the seismogenic zone in the epicentral region of the 26 December 2004 great Sumatra-Andaman earthquake: Results from seismic refraction and wide-angle reflection surveys and thermal modeling. Journal of Geophysical Research: Solid Earth, 115(B1), 2010.

[22] Shuichi Kodaira, Eiji Kurashimo, J-O Park, Narumi Takahashi, Ayako Nakanishi, Seiichi Miura, Takaya Iwasaki, Naoshi Hirata, Kiyoshi Ito, and Yoshiyuki Kaneda. Structural factors controlling the rupture process of a megathrust earthquake at the Nankai trough seismogenic zone. Geophysical Journal International, 149(3):815-835, 2002. 
[23] Shuichi Kodaira, Tetsuo No, Yasuyuki Nakamura, Toshiya Fujiwara, Yuka Kaiho, Seiichi Miura, Narumi Takahashi, Yoshiyuki Kaneda, and Asahiko Taira. Coseismic fault rupture at the trench axis during the 2011 Tohoku-Oki earthquake. Nature Geoscience, $5(9): 646-650,2012$.

[24] Achim J Kopf and Kevin M Brown. Friction experiments on saturated sediments and their implications for the stress state of the Nankai and Barbados subduction thrusts. Marine Geology, 202(3):193-210, 2003.

[25] Heidrun Kopp and Nina Kukowski. Backstop geometry and accretionary mechanics of the Sunda margin. Tectonics, 22(6), 2003.

[26] Jeremy E. Kozdon and Eric M. Dunham. Rupture to the trench: Dynamic rupture simulations of the 11 March 2011 Tohoku earthquake. Bull. Seism. Soc. Am., 103(2B):1275$1289,2013$.

[27] Anne Krabbenhöft, Jörg Bialas, Heidrun Kopp, Nina Kukowski, and C Hübscher. Crustal structure of the Peruvian continental margin from wide-angle seismic studies. Geophysical Journal International, 159(2):749-764, 2004.

[28] Thorne Lay, Charles J Ammon, Hiroo Kanamori, Yoshiki Yamazaki, Kwok Fai Cheung, and Alexander R Hutko. The 25 October 2010 Mentawai tsunami earthquake (Mw 7.8) and the tsunami hazard presented by shallow megathrust ruptures. Geophysical Research Letters, 38(6), 2011.

[29] Gabriel C Lotto and Eric M Dunham. High-order finite difference modeling of tsunami generation in a compressible ocean from offshore earthquakes. Computational Geosciences, 2015.

[30] Shuo Ma and Gregory C Beroza. Rupture dynamics on a bimaterial interface for dipping faults. Bulletin of the Seismological Society of America, 98(4):1642-1658, 2008.

[31] Shuo Ma and Evan T Hirakawa. Dynamic wedge failure reveals anomalous energy radiation of shallow subduction earthquakes. Earth and Planetary Science Letters, 375:113-122, 2013.

[32] Seiichi Miura, Narumi Takahashi, Ayako Nakanishi, Tetsuro Tsuru, Shuichi Kodaira, and Yoshiyuki Kaneda. Structural characteristics off Miyagi forearc region, the Japan Trench seismogenic zone, deduced from a wide-angle reflection and refraction study. Tectonophysics, 407(3):165-188, 2005. 
[33] Yasuyuki Nakamura, Shuichi Kodaira, Becky J Cook, Tamara Jeppson, Takafumi Kasaya, Yojiro Yamamoto, Yoshitaka Hashimoto, Mika Yamaguchi, Koichiro Obana, and Gou Fujie. Seismic imaging and velocity structure around the JFAST drill site in the Japan Trench: low Vp, high Vp/Vs in the transparent frontal prism. Earth, Planets and Space, 66(1):1-12, 2014.

[34] Ayako Nakanishi, Shuichi Kodaira, Seiichi Miura, Aki Ito, Takeshi Sato, Jin-Oh Park, Yukari Kido, and Yoshiyuki Kaneda. Detailed structural image around splay-fault branching in the Nankai subduction seismogenic zone: Results from a high-density ocean bottom seismic survey. Journal of Geophysical Research: Solid Earth, 113(B3), 2008.

[35] Julie Pietrzak, Anne Socquet, David Ham, Wim Simons, Christophe Vigny, Robert Jan Labeur, Ernst Schrama, Guus Stelling, and Deepak Vatvani. Defining the source region of the Indian Ocean Tsunami from GPS, altimeters, tide gauges and tsunami models. Earth and Planetary Science Letters, 261(1):49-64, 2007.

[36] Jascha Polet and Hiroo Kanamori. Shallow subduction zone earthquakes and their tsunamigenic potential. Geophysical Journal International, 142(3):684-702, 2000.

[37] Hugues Raimbourg, Yozo Hamano, Saneatsu Saito, Masataka Kinoshita, and Achim Kopf. Acoustic and mechanical properties of Nankai accretionary prism core samples. Geochemistry, Geophysics, Geosystems, 12(4), 2011.

[38] Demian M Saffer and Chris Marone. Comparison of smectite-and illite-rich gouge frictional properties: application to the updip limit of the seismogenic zone along subduction megathrusts. Earth and Planetary Science Letters, 215(1):219-235, 2003.

[39] Mariko Sato, Tadashi Ishikawa, Naoto Ujihara, Shigeru Yoshida, Masayuki Fujita, Masashi Mochizuki, and Akira Asada. Displacement above the hypocenter of the 2011 Tohoku-Oki earthquake. Science, 332(6036):1395-1395, 2011.

[40] David W Scholl and Roland von Huene. Crustal recycling at modern subduction zones applied to the past - issues of growth and preservation of continental basement crust, mantle geochemistry, and supercontinent reconstruction. Geological Society of America Memoirs, 200:9-32, 2007.

[41] Mark Simons, Sarah E Minson, Anthony Sladen, Francisco Ortega, Junle Jiang, Susan E Owen, Lingsen Meng, Jean-Paul Ampuero, Shengji Wei, Risheng Chu, et al. The 2011 
magnitude 9.0 Tohoku-Oki earthquake: Mosaicking the megathrust from seconds to centuries. Science, 332(6036):1421-1425, 2011.

[42] Keith Smith. Environmental hazards: assessing risk and reducing disaster. Routledge, 2013.

[43] Seth Stein and Emile A Okal. Seismology: Speed and size of the Sumatra earthquake. Nature, 434(7033):581-582, 2005.

[44] Yuichiro Tanioka and Kenji Sataka. Fault parameters of the 1896 Sanriku tsunami earthquake estimated from tsunami numerical modeling. Geophysical Research Letters, 23(13):1549-1552, 1996.

[45] Harold J Tobin and J Casey Moore. Variations in ultrasonic velocity and density with pore pressure in the decollement zone, northern Barbados Ridge accretionary prism. In Proceedings of the Ocean Drilling Program. Scientific results, pages 125-136. National Science Foundation, 1997.

[46] Harold J Tobin, J Casey Moore, and GF Moore. Laboratory measurement of velocity vs. effective stress in thrust faults of the Oregon accretionary prism: Implications for fault zone overpressure. In Proceedings of the Ocean Drilling Program. Scientific results, volume 146, pages 349-358. Ocean Drilling Program, 1995.

[47] Roland von Huene, Ingo A Pecher, and Marc-Andre Gutscher. Development of the accretionary prism along Peru and material flux after subduction of Nazca Ridge. Tectonics, 15(1):19-33, 1996.

[48] Roland von Huene and Cesar R Ranero. Subduction erosion and basal friction along the sediment-starved convergent margin off Antofagasta, Chile. Journal of Geophysical Research: Solid Earth, 108(B2), 2003.

[49] Roland von Huene, Cesar R Ranero, and Dave W Scholl. Convergent margin structure in high-quality geophysical images and current kinematic and dynamic models. In Subduction Zone Geodynamics, pages 137-157. Springer, 2009.

[50] Johannes Weertman. Unstable slippage across a fault that separates elastic media of different elastic constants. Journal of Geophysical Research: Solid Earth, 85(B3):1455$1461,1980$. 